\title{
Development and deployment of public transport policy and planning in Taiwan
}

\author{
LAWRENCE W. LAN ${ }^{1, *}$, MING-TE WANG ${ }^{2} \&$ APRIL Y. KUO ${ }^{3}$ \\ ${ }^{1}$ Institute of Traffic and Transportation, National Chiao Tung University, 4F, 114 Sec. 1, Chung \\ Hsiao W. Rd., Taipei, 10012, Taiwan; ${ }^{2}$ Institute of Transportation, Ministry of Transportation \\ and Communications, Taiwan; ${ }^{3}$ Department of Civil and Environmental Engineering, University \\ of Maryland, College Park, USA \\ (*Author for correspondence, E-mail: lawrencelan@mail.nctu.edu.tw)
}

Key words: policy planning, public transport, sustainable transport, Taiwan

\begin{abstract}
Over the past decade, the escalating roadway congestion and environmental deterioration due to heavy use of private vehicles have provoked the Taiwan government to realize the importance of public transport systems. Under the "carrot-and-stick" rationales, the government has formulated public transport policies and exercised a series of related initiatives by providing sufficient and higher quality of public transport services so as to attract more private vehicle users. In this paper, the planning philosophy and policy formulation of Taiwan's public transport development are highlighted. The most important initiatives, including the Five-year Enhancement of Mass Transportation Program and the upgrading public transport schemes in the National Development Plan are examined. Based on previous experience and lessons, we point out the most challenging issues that the government will encounter. Suggestions for the future of public transport planning are also addressed.
\end{abstract}

\section{Background}

Taiwan is an island $394 \mathrm{~km}$ long and $144 \mathrm{~km}$ wide with a total area of approximately $36,000 \mathrm{~km}^{2}$. Owing to the long and narrow geography with a barrier in the form of the central mountains, the major intercity transportation systems are north-south in direction and circle around the island. The most important urban transportation is concentrated in three metropolitan areas - Taipei, Taichung, and Kaohsiung.

This island country has enjoyed economic growth since the 1970s. The annual growth of gross domestic product (GDP) averaged about $8 \%$ over the past three decades. In order to accelerate economic growth, the Taiwan government has consistently given priority to building highway infrastructures for the convenient movement of people and freight rather than the development of public transport systems. As such, a vicious circle of public-private transport systems was gradually formed. The economic growth provided an initial momentum to increase car ownership and usage. 
More car ownership and usage reduced the demand for public transport, to which the operators responded by either raising the fares or curtailing the frequency or both. The use of cars became more attractive than before and induced more people to purchase cars, thus contributing to the vicious circle. As a consequence, after several cycles (years), car drivers are facing more congestion, buses are running less frequently because of the roadway congestion, and almost everyone is worse off than before.

The trend toward greater use of private vehicles in Taiwan has not only created ubiquitous congestion on the urban roads and intercity highways, but has also resulted in excessive consumption of fuel and the resultant emissions that have damaged the ecological balance. The Taiwan government at various levels had not realized the importance of ameliorating the public transport systems. The first Transportation Policy White Book released in 1995 by the Ministry of Transportation and Communications (MOTC) was a milestone in Taiwan's public transport history. Since then the government has proclaimed it will definitely develop public transportation. Under the guidelines of this White Book, a battery of public transport related initiatives and programs have been implemented. The Five-year Enhancement of Mass Transportation Program was perhaps the most critical one, which has spent nearly NT\$ 15.9 billion (32 NT dollars equivalent to one US dollar) on the improvement of mass transportation systems including intercity, urban, rural, and offshore public transport.

The purpose of this paper is to highlight and critique the most important public transport initiatives recently exercised in Taiwan and to provide our suggestions for future planning. The paper is organized as follows. Section 2 elaborates the intercity and urban public transport scenes in Taiwan with some statistical implications. The planning philosophy and formulation of policy for public transport development are elucidated in Section 3. The deployment of most of the important public transport initiatives and ongoing schemes are narrated in Section 4. Based on previous experience and lessons, we point out the most challenging issues that the government will encounter in Section 5. Finally, we make suggestions for future public transport planning in Section 6 .

\section{Public transport scenes in Taiwan}

Due to rapid economic growth, the number of private vehicles in Taiwan has greatly increased since 1990 while the number of public vehicles has only slightly increased in the same period. Compared with year 1990, the number of passenger cars and motorcycles in 2004 grew by $138 \%$ and $79 \%$, respectively; however, the number of buses grew only by $27 \%$ (Table 1). Private 
vehicles in Taiwan are used for the majority of daily personal trips. According to the 1995 national household interviews and screenline traffic surveys (IOT 1999), of the 34.66-million short-distance (within $50 \mathrm{~km}$ ) daily trips, about $81 \%$ were made by private vehicles and only $19 \%$ by public transportation. Of the 895-thousand long-distance (beyond $50 \mathrm{~km}$ ) daily trips, on the other hand, about $62 \%$ were made by private modes and $38 \%$ by public transportation. These figures imply that while urban public transport services dominate the overall public transport market in Taiwan, intercity travelling has depended much more on the public transport services than the urban travelling.

\subsection{Intercity public transport}

The intercity public transport mainly includes bus, railway, and domestic air flights. Table 2 presents the passenger variations in the intercity public transport market over the past decade. The passengers have declined from 628.7 million in 1993 to 432 million in 2004. The decline is mainly contributed to by the large decrease in bus passengers, as the number of railway and air passengers has remained little changed. Nonetheless, travelling by bus is still the most important mode in Taiwan's intercity transport market today. Of the total intercity passengers in 2004 , for instance, nearly $58.6 \%$ travelled by bus, $39 \%$ by railway and only $2.4 \%$ by air.

Table 1. Number of vehicles registered in Taiwan (1990-2004).

\begin{tabular}{|c|c|c|c|c|c|c|c|c|}
\hline \multirow[t]{2}{*}{ Year } & \multicolumn{2}{|l|}{ Bus } & \multicolumn{2}{|c|}{ Passenger car } & \multicolumn{2}{|l|}{ Motorcycle } & \multicolumn{2}{|l|}{ Total } \\
\hline & Number & Index & Number & Index & Number & Index & Number & Index \\
\hline 1990 & 20,837 & 100 & $2,263,418$ & 100 & $7,145,628$ & 100 & 20,837 & 100 \\
\hline 1991 & 20,120 & 97 & $2,541,364$ & 112 & $7,409,175$ & 104 & 20,120 & 97 \\
\hline 1992 & 21,294 & 102 & $2,900,042$ & 128 & $7,649,311$ & 107 & 21,294 & 102 \\
\hline 1993 & 21,210 & 102 & $3,238,754$ & 143 & $7,867,396$ & 110 & 21,210 & 102 \\
\hline 1994 & 21,252 & 102 & $3,570,497$ & 158 & $8,034,509$ & 112 & 21,252 & 102 \\
\hline 1995 & 21,598 & 104 & $3,874,203$ & 171 & $8,517,024$ & 119 & 21,598 & 104 \\
\hline 1996 & 21,772 & 104 & $4,146,475$ & 183 & $9,283,914$ & 130 & 21,772 & 104 \\
\hline 1997 & 22,743 & 109 & $4,411,911$ & 195 & $10,051,613$ & 141 & 22,743 & 109 \\
\hline 1998 & 22,871 & 110 & $4,545,488$ & 201 & $10,529,040$ & 147 & 22,871 & 110 \\
\hline 1999 & 23,798 & 114 & $4,509,430$ & 199 & $10,958,469$ & 153 & 23,798 & 114 \\
\hline 2000 & 23,923 & 115 & $4,716,217$ & 208 & $11,423,172$ & 160 & 23,923 & 115 \\
\hline 2001 & 24,053 & 115 & $4,825,581$ & 213 & $11,733,202$ & 164 & 24,053 & 115 \\
\hline 2002 & 25,079 & 120 & $4,989,336$ & 220 & $11,983,757$ & 168 & 25,079 & 120 \\
\hline 2003 & 25,628 & 123 & $5,169,733$ & 228 & $12,366,864$ & 173 & 25,628 & 123 \\
\hline 2004 & 26,453 & 127 & $5,390,848$ & 238 & $12,793,950$ & 179 & 26,453 & 127 \\
\hline
\end{tabular}

Source: Statistical Abstract of Transportation and Communications, MOTC (2005). 
Table 2. Intercity public transportation passengers in Taiwan (1993-2004).

\begin{tabular}{|c|c|c|c|c|c|c|c|c|}
\hline \multirow[t]{2}{*}{ Year } & \multicolumn{2}{|l|}{ Bus } & \multicolumn{2}{|l|}{ Railway } & \multicolumn{2}{|l|}{ Air } & \multicolumn{2}{|l|}{ Total } \\
\hline & $\begin{array}{l}\text { Passengers } \\
(1000 \\
\text { persons })\end{array}$ & $\begin{array}{l}\text { Market } \\
\text { share } \\
(\%)\end{array}$ & $\begin{array}{l}\text { Passengers } \\
(1000 \\
\text { persons })\end{array}$ & $\begin{array}{l}\text { Market } \\
\text { share (\%) }\end{array}$ & $\begin{array}{l}\text { Passengers } \\
(1000 \\
\text { persons })\end{array}$ & $\begin{array}{l}\text { Market } \\
\text { share }(\%)\end{array}$ & $\begin{array}{l}\text { Passengers } \\
(1000 \\
\text { persons })\end{array}$ & $\begin{array}{l}\text { Market } \\
\text { share } \\
(\%)\end{array}$ \\
\hline 1993 & 471,358 & 74.98 & 157,295 & 25.02 & $\mathrm{~N} / \mathrm{A}$ & $\mathrm{N} / \mathrm{A}$ & 628,653 & 100 \\
\hline 1994 & 466,247 & 74.41 & 160,330 & 25.59 & $\mathrm{~N} / \mathrm{A}$ & $\mathrm{N} / \mathrm{A}$ & 626,577 & 100 \\
\hline 1995 & 443,539 & 73.49 & 159,981 & 26.51 & $\mathrm{~N} / \mathrm{A}$ & $\mathrm{N} / \mathrm{A}$ & 603,520 & 100 \\
\hline 1996 & 402,917 & 69.48 & 159,439 & 27.49 & 17,564 & 3.03 & 579,920 & 100 \\
\hline 1997 & 367,968 & 66.68 & 165,233 & 29.94 & 18,607 & 3.38 & 551,808 & 100 \\
\hline 1998 & 347,099 & 64.80 & 171,868 & 32.09 & 16,670 & 3.11 & 535,637 & 100 \\
\hline 1999 & 319,150 & 61.69 & 182,181 & 35.21 & 16,052 & 3.10 & 517,383 & 100 \\
\hline 2000 & 313,033 & 60.47 & 191,478 & 36.99 & 13,118 & 2.54 & 517,629 & 100 \\
\hline 2001 & 286,168 & 59.09 & 186,079 & 38.42 & 12,056 & 2.49 & 484,303 & 100 \\
\hline 2002 & 278,609 & 59.95 & 175,341 & 37.73 & 10,748 & 2.32 & 464,698 & 100 \\
\hline 2003 & 249,726 & 59.30 & 161,426 & 38.33 & 9,949 & 2.37 & 421,101 & 100 \\
\hline 2004 & 253,108 & 58.59 & 168,473 & 39.00 & 10,436 & 2.41 & 432,017 & 100 \\
\hline
\end{tabular}

Source: Statistical Abstract of Transportation and Communications, MOTC (2005).

By ignoring air transportation, Table 3 further compares the passengerkilometers and average trip length by bus and railway. Note that the total intercity passenger-kilometers have reduced by $18 \%$ from 1993 to 2004, with a $31 \%$ decrease by bus but a $2 \%$ decrease by railway. By contrast, the average trip length by bus has increased by $36 \%$ but the railway has a $9 \%$ decrease. In 2004, the average trip length by railway is $55.55 \mathrm{~km}$ and by bus $36.82 \mathrm{~km}$. These figures explain the fact that the railways mainly serve medium- to long-distance passengers while the buses mainly serve the shortto medium-distance trips. Note that the average trip length by intercity bus has increased since 1998 due to the open policy with regard to the freeway coach market: more long-distance freeway coach carriers have started to operate since then.

The intercity bus carriers in Taiwan provide services on both freeways and on local highways. Freeway coach routes link the major cities in the western corridor mainly through Freeways 1 and 3; while local highway bus routes provide services between local cities and rural or mountain areas. A good number of the bus carriers use both freeway and local highway routes. By the end of 2004, there were a total of 53 intercity bus carriers running about 1900 routes with 7147 buses. Compared with the local routes, the freeway routes have much longer mileage and are equipped with more luxurious fleet facilities. Although the total number of intercity bus passengers still decreased after 1995 (Table 2), the open policy towards the freeway coach market had increased the average trip length as presented in Table 3. According to a recent survey (IOT 2000), this open policy had essentially 
Table 3. Intercity public transportation passenger trip length in Taiwan (1993-2004).

\begin{tabular}{|c|c|c|c|c|c|c|}
\hline \multirow[t]{2}{*}{ Year } & \multicolumn{2}{|l|}{ Bus } & \multicolumn{2}{|l|}{ Railway } & \multicolumn{2}{|l|}{ Total } \\
\hline & $\begin{array}{l}\text { Passenger-km } \\
(1000 \\
\text { person-km) }\end{array}$ & $\begin{array}{l}\text { Average Trip } \\
\text { Length }(\mathrm{km})\end{array}$ & $\begin{array}{l}\text { Passenger-km } \\
(1000 \\
\text { person-km) }\end{array}$ & $\begin{array}{l}\text { Average Trip } \\
\text { Length }(\mathrm{km})\end{array}$ & $\begin{array}{l}\text { Passenger-km } \\
(1000 \text { person-km) }\end{array}$ & $\begin{array}{l}\text { Average Trip } \\
\text { Length }(\mathrm{km})\end{array}$ \\
\hline 1993 & $12,969,729$ & 27.52 & $9,542,119$ & 60.66 & $22,511,848$ & 35.81 \\
\hline 1994 & $11,924,890$ & 25.58 & $9,505,488$ & 59.29 & $21,430,378$ & 34.20 \\
\hline 1995 & $10,540,985$ & 23.77 & $9,488,728$ & 59.31 & $20,029,713$ & 33.19 \\
\hline 1996 & $9,771,700$ & 24.25 & $8,968,501$ & 56.25 & $18,740,201$ & 33.32 \\
\hline 1997 & $8,610,631$ & 23.40 & $9,253,845$ & 56.00 & $17,864,476$ & 33.50 \\
\hline 1998 & $8,332,929$ & 24.01 & $9,784,134$ & 56.93 & $18,117,063$ & 34.91 \\
\hline 1999 & $7,924,516$ & 24.83 & $9,977,769$ & 54.77 & $17,902,285$ & 35.71 \\
\hline 2000 & $8,584,250$ & 27.42 & $10,577,132$ & 55.24 & $19,161,382$ & 37.98 \\
\hline 2001 & $8,947,544$ & 31.27 & $10,036,882$ & 53.94 & $18,984,426$ & 40.20 \\
\hline 2002 & $9,655,450$ & 34.66 & $9,665,658$ & 55.12 & $19,321,108$ & 42.56 \\
\hline 2003 & $8,866,424$ & 35.50 & $8,726,391$ & 54.06 & $17,592,815$ & 42.79 \\
\hline 2004 & $9,320,501$ & 36.82 & $9,358,916$ & 55.55 & $18,679,417$ & 44.31 \\
\hline
\end{tabular}

Source: Statistical Abstract of Transportation and Communications, MOTC (2005).

invited more competition and thereby improved the service quality and significantly increased the number of freeway coach passengers.

The railway networks in Taiwan encircle the whole island. Taiwan Railway Administration (TRA), the sole public rail operator, currently operates $1093 \mathrm{~km}$ rail lines, of which $589 \mathrm{~km}$ are double-track. The lines in the western corridor are double-track, $25 \mathrm{KV}$-electrified, and link the major urban centers with express passenger train services. Most of the lines in the eastern corridor are still single-track and not electrified; however, they play a vital role in the intercity transportation because of the low development of land use and highway networks in that area.

\subsection{Urban public transport}

Urban public transport in Taiwan is dominated by bus and metro. The public transport system in the Taipei metropolitan area is much better than that of any other cities in Taiwan. By the end of 2004, Taipei had 15 bus carriers with a total of 3745 buses running on 280 routes. Taipei was the earliest city in Taiwan that introduced the exclusive bus lane in 1990. Currently, there are 10 exclusive bus lanes reaching $50.28 \mathrm{~km}$, which have effectively raised the bus operating speed and reliability. According to a before-and-after survey conducted in 1996 and 1997, the average bus running speed has increased by $47 \%$ and $41 \%$, respectively, during the morning and afternoon peak hours. Moreover, due to the reduction of movement conflicts between 
buses and other vehicles, the average running speed for passenger cars has also increased by $8 \%$ and $7 \%$ during the same rush hours. As a consequence, bus operators have benefited from an increase of frequency by $2.55 \%$, an increase of patronage by $2.31 \%$, and an increase of per kilometer fare-box revenue by $0.07 \%$. Moreover, the number of bus-involved accidents per million bus-kilometers traveled has decreased by $15.23 \%$ because of the simplification of mixed traffic (Chen et al. 2002).

The first medium-capacity rapid transport line (the Mucha Line) in Taipei was opened for commercial service in March 1996, ushering transportation in Taiwan into a new public transport era. The first heavy-capacity metro line (the Tamshui Line) started to operate in March 1997. By the end of 2002, another four metro lines, including the Hsintien Line, Chungho Line, Pannan Line, and Hsiao Nanmen Line, began to operate. The current metro network amounts to $67.2 \mathrm{~km}$ and includes 61 stations. Over the past few years, the Taipei metro system has successfully attracted a great number of passengers from 40 thousands per day in 1996 to 960 thousands per day in 2004 (Table 4). The number of bus passengers in Taipei declined each year before the first rapid transport line was opened; however, it had a slight increase from 1996 to 1999 and again in the year 2001 due to the successful integration with the metro, which includes the adjustment of parallel bus routes, the launching of feeder bus routes, and the discounted transfer fare (originally only from metro to bus, but now also from bus to metro). As indicated in Table 4, the metro lines have certainly enlarged the public transport pie in Taipei. According to the latest survey by the Department of Transportation, Taipei City Government (2002), the market share of public transport in the Taipei metropolitan area has reached $46 \%$ in 2002.

\section{Planning philosophy and policy formulation}

As mentioned above, the ever-increasing traffic congestion and related environmental impact due to more private vehicles usage and less demand for public transport have accompanied economic growth in Taiwan. As such, a private-public transport vicious circle has been created. In order to break or reverse the direction of such a vicious circle, giving the bus preferential treatment such as exclusive lanes in congested areas was strongly advocated by many local transportation professionals and scholars in order to enhance bus operating efficiency and service reliability. Meanwhile, providing subsidies and tax exemption or reduction to the transit operators was also strongly recommended by the transportation experts in order to lower the transit operating costs and the pressure of fare increase. Also strongly recommended was the raising of out-of-pocket expenses of private vehicle owner- 
Table 4. Bus and metro passengers in Taipei (1990-2004).

\begin{tabular}{|c|c|c|c|c|c|c|c|c|}
\hline \multirow[t]{2}{*}{ Year } & \multicolumn{3}{|l|}{ Bus } & \multicolumn{3}{|l|}{ Metro } & \multicolumn{2}{|l|}{ Total } \\
\hline & $\begin{array}{l}\text { Passengers } \\
\text { (persons/per } \\
\text { day) }\end{array}$ & $\begin{array}{l}\text { Growth } \\
\text { rate }\end{array}$ & $\begin{array}{l}\text { Market } \\
\text { share }\end{array}$ & $\begin{array}{l}\text { Passengers } \\
\text { (persons/per } \\
\text { day) }\end{array}$ & $\begin{array}{l}\text { Growth } \\
\text { rate }\end{array}$ & $\begin{array}{l}\text { Market } \\
\text { share }\end{array}$ & $\begin{array}{l}\text { Passengers } \\
\text { (persons/per } \\
\text { day) }\end{array}$ & $\begin{array}{l}\text { Growth } \\
\text { rate }\end{array}$ \\
\hline 1990 & $2,163,496$ & - & $100 \%$ & - & - & - & $2,163,496$ & - \\
\hline 1991 & $2,142,036$ & $-0.99 \%$ & $100 \%$ & - & - & - & $2,142,036$ & $-0.99 \%$ \\
\hline 1992 & $2,110,670$ & $-1.46 \%$ & $100 \%$ & - & - & - & $2,110,670$ & $-1.46 \%$ \\
\hline 1993 & $2,036,008$ & $-3.54 \%$ & $100 \%$ & - & - & - & $2,036,008$ & $-3.54 \%$ \\
\hline 1994 & $1,900,948$ & $-6.63 \%$ & $100 \%$ & - & - & - & $1,900,948$ & $-6.63 \%$ \\
\hline 1995 & $1,753,829$ & $-7.74 \%$ & $100 \%$ & - & - & - & $1,753,829$ & $-7.74 \%$ \\
\hline 1996 & $1,779,248$ & $1.45 \%$ & $98 \%$ & 40,159 & - & $2 \%$ & $1,819,408$ & $3.74 \%$ \\
\hline 1997 & $1,864,505$ & $4.79 \%$ & $95 \%$ & 101,213 & $152 \%$ & $5 \%$ & $1,965,718$ & $8.04 \%$ \\
\hline 1998 & $1,919,315$ & $2.94 \%$ & $92 \%$ & 166,524 & $65 \%$ & $8 \%$ & $2,085,839$ & $6.11 \%$ \\
\hline 1999 & $1,979,745$ & $3.15 \%$ & $85 \%$ & 347,814 & $109 \%$ & $15 \%$ & $2,327,559$ & $11.59 \%$ \\
\hline 2000 & $1,856,135$ & $-6.24 \%$ & $72 \%$ & 733,847 & $111 \%$ & $28 \%$ & $2,589,982$ & $11.27 \%$ \\
\hline 2001 & $1,865,447$ & $0.50 \%$ & $70 \%$ & 793,542 & $8 \%$ & $30 \%$ & $2,658,989$ & $2.66 \%$ \\
\hline 2002 & $1,773,647$ & $-4.92 \%$ & $67 \%$ & 888,859 & $12 \%$ & $33 \%$ & $2,662,506$ & $0.13 \%$ \\
\hline 2003 & $1,677,559$ & $-5.42 \%$ & $66 \%$ & 866,272 & $-3 \%$ & $34 \%$ & $2,543,831$ & $-4.46 \%$ \\
\hline 2004 & $1,712,033$ & $2.06 \%$ & $64 \%$ & 959,509 & $11 \%$ & $36 \%$ & $2,671,553$ & $5.02 \%$ \\
\hline
\end{tabular}

Source: The Statistics Summary of Taipei City, Taipei City Government (2005).

ship and usage to reflect the external costs. Under such a "carrot-and-stick" philosophy, the policy for developing public transport in Taiwan was formulated. This rationale was clearly documented in the first Transportation Policy White Book (MOTC 1995). This document was the first transportation policy book in Taiwan that definitely proposed to develop public transport. Following this White Book, the most important initiative - the Five-year Enhancement of Mass Transportation Program - was implemented. To cope with environmental change, the first White Book was revised in 2002. More explicit policies and strategies for the development of public transport were clearly outlined in the revised White Book (MOTC 2002).

Laying down the legislation was thought to be the most fundamental task for the fulfilment of public transportation policy. After many debates and lengthy discussions, the Public Transportation Development Act (PTDA) was eventually promulgated in May 2002. According to this Act, the government would subsidize the capital investment and operation deficit to those routes serving in the remote districts, such as offshore islands, mountain and rural areas. PTDA also requires the regulatory agencies to conduct periodical levelof-service assessment on the operation of public transportation systems. In order to increase the attraction of public transport, PTDA pushes for constructing more exclusive bus lanes and public transport terminals and for integrating the tickets and schedules of the various transport systems. Moreover, PTDA permits public transport carriers to charge full fare for any 
passenger. The discount concession for special passengers, such as the aged and the handicapped, previously cross-subsidized by the full-fare passengers in old days, would now be subsidized from the government budget.

Providing higher quality public transport services to attract more passengers away from private vehicles was considered as a general policy guideline of the White Book. Constructing new metro or light rail systems was regarded as one of the most important policies. For example, the largest public transport project in Taiwan, a high-speed railway linking the major cities in the western corridor, is under construction. With the experience of the rapidity, punctuality, and high capacity of the Taipei metro, the government is also considering various types of rapid transport systems in different urbanized areas such as Taoyuan, Hsinchu and Taichung as well as a fast line linking the CKS International Airport at Taoyuan to Taipei. To encourage more people to use public transport, the government also endeavors to improving the transport service quality by implementing the integration of ticketing systems, schedules and transfer terminals, providing more exclusive lanes for buses, directly subsidizing the remote deficit routes, and keeping the freeway coach market open.

\section{Deployment of public transport initiatives}

Under the policy guidelines in the White Book, the Taiwan government has facilitated a series of public transport initiatives since 1995. Of these deployments, the so-called Five-year Enhancement of Mass Transportation Program is viewed as the most critical one. Furthermore, the public transportation schemes in the National Development Plan, released in May 2002, have sketched the ongoing and near-future deployments for public transport in Taiwan. We highlight these deployments in the following.

\subsection{The five-year enhancement of mass transportation program}

In order to improve the mass transportation services and to assist those operators with a financial crisis or an operational difficulty, the Five-year Enhancement of Mass Transportation Program, approved by the Executive Yuan, was implemented by MOTC from 1996 to 2001. In this program, the tax/fee exemption has greatly ameliorated the bus operators' financial crises, the direct subsidy has offered the money needed to keep deficit routes in service, the periodical operational appraisal has ensured the quality of the services, the lift of an entrance barrier has encouraged competition in the freeway coach market, and the introduction of more exclusive lanes has also improved the efficiency and effectiveness of bus operation. This program has 
been viewed as the most important public transport action plan in Taiwan's public transport history (Chang 2002).

One of the undertakings in this five-year enhancement program was to subsidize deficit transit routes, starting from July 1996. This subsidy was the first attempt in Taiwan's public transportation history. Up to the end of 2001, the subsidies to intercity and urban bus carriers amounted to NT\$ 3958 and 2330 million, respectively. The direct subsidy has in effect kept many deficit routes in service, especially in rural and mountain areas. In addition, to help reduce the operation costs, the government has exempted the buses from the fuel and license plate taxes since 1996. The taxes saved by all the bus carriers amounted approximately to NT\$ 3 billion from 1996 to 2001. The government has also exempted the freeway tolls for the bus carriers since February 1997. Up to the end of 2001, the total tolls saved amounted to NT\$ 1.5 billion. These exemption tactics have effectively enabled the bus carriers to resist their financial difficulties.

Another important undertaking related to this five-year enhancement program was the "open market" for freeway transit intercity routes. Prior to 1980 , there was only one government-owned carrier, the Taiwan Motor Transport Company, who monopolized the freeway passenger services. This monopoly proved to have insufficient capacity and thus motivated an ever-increasing number of "illegal" coaches entering the freeway market. The "illegal" coaches provided better frequency with much higher quality than the monopoly on busy routes. In dealing with the everincreasing "illegal" coaches, which had sometimes caused other social problems (e.g., criminal squabbling for the territory), the government was "forced" to approve the second freeway transit operator, the United Bus Company, by bringing together most of the existing "illegal" carriers in 1990. However, this action failed to prevent more luxurious "illegal" coaches from entering the excess profit routes with insufficient service capability offered by the duopoly companies (Lan and Wang 2002). During several public hearings held by lawmakers, almost all the transportation scholars and specialists consistently supported the "open market" policy because they thought the competition would invite higher quantity and quality of freeway transport services: this would attract more automobile users and mitigate the serious freeway congestion and related environmental impact. MOTC finally opened up the freeway market in 1995, the same year the first White Book was released. This small step was in effect a giant leap forward and broke the prevailing strict protection of existing transit operators in Taiwan. By the end of the five-year enhancement program, the number of freeway coach carriers had increased from 2 to 33 offering 140 routes. According to a recent survey (IOT 2000), the freeway 
market deregulation has significantly promoted competition; as a consequence, the service quality and fleet capacity have greatly improved and the number of freeway passengers has considerably increased.

\subsection{The ongoing deployments}

The planning philosophy of Taiwan's public transport policies is based on the theory that good public transport can not only mitigate the traffic congestion but also benefit the society at large. The National Development Plan, recently released by the Council for Economic Planning and Development in May 2002 , is the most critical proposal to sketch the near future of Taiwan to the end of 2008. In this plan, one strategy for upgrading the public transportation systems is the continuation of the five-year enhancement program that was ended in June 2001. This upgrading strategy appends a predetermined budget of NT\$ six billion from 2004 to 2008, and involves the following public transit development schemes: (1) provide the local governments with budgets to enable them to plan service integration among different public transport systems; (2) provide the budget for building public transit terminals; (3) provide the local governments with financial assistance to construct exclusive bus lanes; (4) provide the budget for implementing bus service appraisal every 2 years; (5) subsidize the bus carriers to enable them to invest in purchasing new buses; (6) subsidize the bus carriers for the creation of electronic ticketing systems; and (7) subsidize the operating deficits of bus routes serving remote areas.

To correct the previously under-supplied public transport infrastructures, the Taiwan government has approved the introduction of more guideway systems. In Taipei, six metro lines have been opened for service, but the initial metro network still has two more lines and two extensions under construction and one line at the detailed design stage. For the proposed expanded network, five more new lines and some extensions of the existing lines amounting to $67.7 \mathrm{~km}$ will be constructed in the coming 10 years. By then, the total length of the Taipei metro system will reach $134.9 \mathrm{~km}$. The initial network of Kaohsiung Rapid Transit System is $42.7 \mathrm{~km}$ long including the Red Line and the Orange Line. Along these two lines, there are 38 stations, of which 28 are underground, two at ground level and eight elevated. The Kaohsiung metro project is a build-operate-transfer (BOT) project and is expected to provide high capacity and quality service for most commuters in the Kaohsiung area at the end of 2006.

The high-speed rail, with $345 \mathrm{~km}$ connecting 14 major cities, is the largest transportation infrastructure as well as the first major public construction project in Taiwan funded by private investment. It is capable of carrying 
over 300,000 passengers per day and of reaching an operating speed as high as $300 \mathrm{~km} \mathrm{~h}^{-1}$, which would shorten the north-south journey time from Taipei to Kaohsiung to less than $90 \mathrm{~min}$. This project is under a BOT concession contract and is about to open for service soon.

\section{Comments}

As mentioned in the previous sections, the Taiwan government has undertaken a series of public transport initiatives over the past years. Some of them are thought effective but some others are not. Quite a few strategies mentioned in the White Book have been applied only to a limited extent or are without any implementation plans at all. The most challenging issues that the government will encounter are described as follows.

\subsection{Inadequate "stick" upon private vehicles}

Reducing the heavy use of private vehicles has been set in the first White Book as one of the policy goals; however, the realization is yet to be accomplished. Accurately reflecting the private vehicle "external" costs by imposing higher taxes or raising parking fees is not satisfactorily put into practice in most jurisdictions, mainly for political reasons. Other restraining tactics, such as requiring the possession of a parking space before being entitled to own a car, or imposing congestion tolls on private vehicles entering the CBD (similar to Singapore's electronic road pricing or London's congestion toll), are now under study and are very controversial. The even more challenging issue is that Taiwan has recently become a member of the World Trade Organization (WTO), and so the request to lower custom duties for automobiles imported from other member countries is surely unfavorable to restraining the continuing growth of the use of private vehicles.

\subsection{Insufficient budgets for public transport development}

While the subsidies in the five-year enhancement program have lessened the transit carriers' financial difficulties, a recent investigation (Lan et al. 2003) showed that nearly two-thirds of the intercity bus carriers had operational deficits in 2001. The cost-efficiency and service-effectiveness indices also showed that over half of the intercity bus carriers suffered from relatively low efficiency and/or low effectiveness. This suggests that many bus carriers are still operating under difficult circumstances, despite having continuously received annual subsidies from the government since 1996. For instance, Taiwan Motor Transport Company, the only government-owned intercity bus 
carrier, used to suffer from an annual operational deficit of up to NT\$ 4.9 billion before it was successfully privatized in January 2002. One private carrier in southern Taiwan, the Tainan Bus Company, which used to run both intercity and city routes, shut down all of its city route services in 2002 because of near bankruptcy. Another private carrier, the Taichung Bus Company, yielded most of its shareholding to a new buyer in 2003 due to a serious financial crisis. The Taipei City Bus Administration, a governmentowned city bus carrier, which used to operate with an annual deficit of over NT\$ 1.5 million, was successfully privatized in January 2004. It was believed that more private bus carriers would have shut down their services, had the subsidy program not been carried out. Moreover, the debates about equity and efficiency of resource allocation have existed since the subsidy began. While preplanning the annual subsidy budgets, the central and local governments had to justify their equity and efficiency in answer to questions by some lawmakers, councillors and economists. This also makes the subsidy budget unstable for the future. The subsidy budget has continued but has been shrinking year by year after the five-year enhancement program, thus never satisfying the needs of the bus carriers. Looking for sufficient support and sources of subsidy should be regarded as important issues for the future development of public transport.

\subsection{Reformation of and new challenges for conventional railways}

Since the year 1978 when the Taiwan Railway Administration (TRA) first suffered from an operation deficit, the government has attempted to solve this problem. It has long been recommended that TRA be reformed as a rail corporation first and then privatized later. However, the reformation has encountered strong resistance from the labor union. First, the rail corporation was not clear whether or not to split the rail track infrastructures from the rolling stock operation company. It was thought that the government should be responsible for the construction and maintenance of infrastructures in view of the heavy capital investment needed. However, the controversial outcomes of several foreign railway reformation experiments affected the decision-making. Second, dealing with the huge amount of deficit was thought a prerequisite for reformation but TRA did not have the capability to bear such huge debts. Because the historical debts came mostly from the ever-increasing retired employees' monthly allowances and the loss of rural lines and stations, the government was requested to take full responsibility for those debts and the retired employees' allowances. Third, the labor union fought vigorously for the privileges and rights of the existing employees during the reforming process. TRA will soon face brutal competitions from the upcoming high-speed rail, which is about to skim off TRA's most profitable 
intercity markets. This can make the TRA reformation more urgent and even more complicated.

\subsection{Potential terrorist attacks on public transport}

While transportation security has been important from the time trade and travel by land, sea and air started, the horrendous event of 11 September 2001 will perhaps remain rooted in the memory of our generation. The terrorist threat had evidently been shifting from military, diplomatic and other protected hard targets to civilians, residences and other unprotected soft targets. To survive and succeed in the post-9/11 environment, the terrorist groups have been changing their terrorist priorities and strategies (Lan 2003). These violent terrorist attacks have gradually been shifting from civil aviation to land transportation, especially to the crowded railway and subway systems. Recent "bomb incidents" occurring in TRA trains are just such examples of the suspected attacks. Potential terrorist attacks on public transport have become a worldwide problem, not limited by geographical or political boundaries. Thus, the security of public transport is a new challenging issue that the government and carriers must face.

\subsection{The impact of political conflicts on direct transport between Taiwan and the Mainland}

At the moment, direct transportation between Taiwan and Mainland China is in an impasse because of the long-existing political conflicts between both sides. Currently, the aircraft on one side are not allowed to go to the other side, but the vessels carrying cargos from one side can reach the other side's "off-shore" destinations via a third region, such as Hong Kong. This indirect transportation has caused tremendous extra transportation times and costs, which has lowered both sides' economic efficiency and market competition. Due to increasing labor costs, traditional labor-intensive industries in Taiwan have steadily been moved to neighboring countries, including Mainland China, Thailand, Indonesia, the Philippines, Malaysia, and Vietnam. Of these countries, Mainland China is now dominating Taiwan investors; thus, the demands for cross-strait trade and travel have been rapidly growing in the past few years. Consequently, the two governments are under greater pressure than before from the mounting number of business people and tourists requesting direct transportation. We anticipate that direct transportation between Taiwan and the Mainland will be possible in the near future. This will surely affect the capacities of current airports, ports, and airline and maritime carriers. It can also bring about an unexpected increase of intercity 
travel demands, particularly from the airports or ports to the major cities, if Mainland people are allowed to enter Taiwan with less restriction. Hence, re-examination of the intercity public transport systems with consideration of the effects of two-strait direct transportation can be another challenging issue for future public transport planning in Taiwan.

\section{Suggestions}

The future economic growth of Taiwan is expected to be rosy because of the development of more and more technology-intensive industries. Lowering the custom duties for automobiles and fuel imported from WTO member countries is inevitable. Consequently, one can anticipate that the steady increase in private vehicle ownership and usage may cause another vicious public-private transport circle. Taiwan needs more effective and robust "carrot-and-stick" transportation strategies and action plans in the future. On one hand, exact reflections of the "external" costs by imposing higher usage fees and by enforcing necessary restrictions on private vehicle usage and/or ownership should be considered seriously. On the other hand, provision of higher quality, lower priced and more accessible public transport services than before should also be imperative for future public transport planning in Taiwan. Based on these underlying principles and to meet the above-mentioned challenging issues, we propose the following suggestions to further upgrade the public transport systems in Taiwan.

\subsection{Adopt transit-oriented development (TOD) planning and green public transport modes accessible to all users}

It has been argued that the transportation systems are nowadays not sustainable because of excessive traffic fatality, ubiquitous roadway congestion, and serious air pollution. The worldwide concern about the limited gasoline reserves and atmospheric greenhouse effect have led to the TOD concept for future sustainable planning. We recommend that the Taiwan government amalgamate the TOD concept into land use and transportation planning. We also suggest that the government offer more incentives to encourage the use of green public transport modes with less energy consumption, less emissions, and accessible to all users including the aged and handicapped.

\subsection{Build more rapid transport systems}

Taipei exclusive bus lanes and the metro system have successfully attracted millions of daily users, which in effect eased the traffic congestion and the 
related environmental impact. In other metropolitan areas, such as Taoyuan, Taichung and Kaohsiung, where population exceeds one million but the public transit services are not well supplied and the traffic congestion and related impact have already been severe, we recommend giving priority to building metro systems. In other urban areas that do not have enough demand for the support of expensive metro systems, we would recommend other rapid transit alternatives, such as exclusive bus lanes, rapid bus transit, light railway trains or the like. BOT concessions could be a good means of accelerating the provision of rapid transit systems; however, due to serious financial problems, one BOT firm had postponed the construction of a rapid transit line connecting Taipei to CKS International Airport for several years; thus the government turned down that contract and completely took it over. The government should learn a lesson from this case and pay more attention to firms' financial capability to carry out future BOT projects.

\subsection{Integrate the intercity and urban public transport systems}

Due to successful integration with the metro lines, the Taipei bus systems have experienced an increase in passengers despite the opening of the metro line by line. Routes, tickets, and fares have played the major roles in the integration. Previous parallel bus routes were modified or removed to become the feeders of the metro. A significant fare discount for two-direction transfers, via the same contactless smart IC-card ticketing system, has attracted more passengers to use both bus and metro systems. It is an example of success and good evidence that bus and metro can become of complementary, rather than conficting, provided that the two systems integrate properly. This successful experience should also be brought to bear on other future systems such as the Kaohsiung metro and the high-speed rail. The intercity transportation in the western corridor will soon be a new situation after the opening of high-speed rail. Based on the experience from Japanese Shinkansen and European high-speed trains, domestic aviation may well be impacted most profoundly. Other intercity public transport services, including TRA and long-distance freeway coach routes, may be affected too. To avoid wastage of resources, we recommend that the government redirect domestic aviation to offshore islands and international markets (including direct flights to Mainland China) as soon as possible. It is thought that high-speed rail should mainly target the long-distance passengers; and TRA or freeway coach services should concentrate on the short- to medium-distance markets. Of course, both TRA and freeway coaches can also become the feeders of the high-speed railways. We therefore recommend that the government promote service integration among different intercity and urban public transit systems and build adequate public transit terminals to facilitate passenger transfers. 


\subsection{Provide sufficient funds for public transport development}

As mentioned above, the Taipei bus systems have experienced an increase in passengers because of the successful integration with the metro. The most critical successful factor is perhaps the significant fare discount (NT\$ 8) to each passenger transferring from metro to bus or from bus to metro within $1 \mathrm{~h}$. Both the Taipei city and the county governments have budgeted to subsidize this transfer discount each year. Moreover, the Taipei city government has also designated annual budgets to match the central government's subsidies in the Five-year Enhancement Program and the newly promulgated Public Transportation Development Act. However, in other cities or counties, the local governments may not have enough budgets for the same purpose. Even at the central government level, the allocated budget for public transport is not always sufficient. We recommend that the governments at the different levels designate enough budgets to assist and subsidize the public transport systems including the application of intelligent transportation systems and, at the same time, effectively monitor their service quality and efficiency. This paper does not perform in-depth analysis by comparing the before-and-after effectiveness of the Five-Year Enhancement Program: a comprehensive study is needed to get more insight into the change in public transit efficiency and productivity growth as a result of the enhancement program. This study would enable useful policy revision in planning future public transport initiatives.

\subsection{Reform the TRA}

TRA has been suffering from a deficit since 1978, the year that the first freeway was opened to traffic. The annual deficit has increased to over NT\$ 10 billion since 1998. Therefore, innovation and reformation for the TRA have been fervently advocated. Because TRA is viewed as a public entity, all of its retired employees have enjoyed lifetime monthly allowances, very similar to the lifetime monthly pensions for retired civil servants. The annual deficit for TRA will be drastically increased because of the very substantial interest to be paid on the cumulative debts and the escalating amounts of allowances for the retired. This unreasonable retired-allowance system can lead any firm to bankruptcy because of the "snow-ball effect" - more and more retired employees will ultimately accumulate. We recommend that the government adopt the successful models in privatizing the former Taiwan Motor Transport Company and Taipei City Bus Administration by offering the TRA's current 15-thousand employees a so-called "six plus one" incentive bonus (i.e., 7 month extra salary) to encourage them either to retire by taking away the bonus or to invest the bonus in the newly established private railway corporation. Meanwhile, the government should look for 
another budget to completely offset the cumulative debts of the TRA and to immediately cease the lifetime retired-allowance system. The former 16-thousand retired TRA employees should no longer receive lifetime monthly allowances; instead, they should be paid directly by the government with once-and-for-all compensation.

\subsection{Protecting the public transport systems from terrorist attacks}

In the post-9/11 environment, terrorist attacks have had a tendency to shift from civil aviation to crowded public transportation systems such as the metro and conventional rail in every country. We recommend that the government authorities issue new requirements and assist the public transport operators to work out effective measures and introduce innovative technological solutions to prevent such attacks. The government should require all public transport operators to exercise anti-terrorism drills and to undergo training programs periodically on how to respond to bomb threats, biochemical threats, and arson etc.

\subsection{Accelerate direct transport between two straits}

To be win-win on two straits, both the Taiwan and the Mainland governments are urged to start peaceful-talks as soon as possible about such topics as trade, marriage, tourism, crime prevention and cultural exchange without altering the political status quo. Since all of these topics are related to direct transportation, we recommend that both governments start with special security code systems that can identify the civil aircraft and vessels along the designated routes. Furthermore, the restrictive regulations on people and cargo movements between the two sides should be lifted step by step.

\section{Acknowledgements}

The authors wish to thank two anonymous referees' constructive comments and stimulating suggestions on the original manuscript.

\section{References}

Chang SK (2002) A review on public transportation policy in Taiwan. Transactions for the Chinese Institute of Engineers 75(2): 3-16.

Chen WC, Chen RM \& Shen SH (2002) Current status and future visions for Taipei bus exclusive lanes. Transactions for the Chinese Institute of Engineers 75(2): 103-114. 
Department of Transportation (2002) Taipei City Transportation Policy. Taipei City Government. Institute of Transportation (1999) The Third Taiwan Area Integrated Transportation Systems Planning Study - Part III: Transportation Demand Analysis, Research Report, Ministry of Transportation and Communications, ROC.

Institute of Transportation (2000) Evaluation of the Benefit from Deregulation of Freeway Bus Service and Review of the Implementation of Deregulation Scheme, Research Report, Ministry of Transportation and Communications, ROC.

Lan LW \& Wang MT (2002) Deployment and development of Taiwan highway passenger carriers. Transactions for the Chinese Institute of Engineers 75(2): 86-102.

Lan LW (2003) The New Challenge of International Transportation Security, Institute of Traffic and Transportation. Taipei: National Chiao Tung University Press.

Lan LW, Wang MT, Chen CH \& Kuo AY (2003) Operation Difficulties and Breakthroughs for Taiwan Highway Bus Industry, Research Report, the United Association of Taiwan Area Bus Companies.

Ministry of Transportation and Communications $(1995,2002)$ Transportation Policy White Book, ROC.

Ministry of Transportation and Communications (2005) Statistical Abstract of Transportation and Communications, ROC.

\section{About the authors}

Lawrence W. Lan is a professor at the Institute of Traffic and Transportation, National Chiao Tung University, Taiwan. His recent research interests include the formation of traffic patterns with cellular automaton simulations, nonlinear phenomena and prediction of traffic dynamics, and advanced traffic control algorithms.

Ming-Te Wang is a researcher at the Institute of Transportation, Ministry of Transportation and Communications, Taiwan. He is also a Ph.D. candidate at ITT, NCTU. His research work deals with the operational issues and advanced controls of public transportation with artificial intelligence methods.

April Y. Kuo is a Ph.D. candidate at the Department of Civil and Environmental Engineering, University of Maryland, College Park. She used to work as an assistant researcher at ITT, NCTU before moving to the USA. Her research interests include fuzzy neural networks and integral capacitated multicommodity network flow problems. 